\title{
Spatial Model of Traffic Congestion by the Changes on City Transportation Route
}

\author{
S.Supriatna ${ }^{\mathrm{a}, 1}$, M. Dimyati ${ }^{\mathrm{a}}$, Dede Amrillah ${ }^{\mathrm{a}, \mathrm{b}}$ \\ ${ }^{a}$ Department of Geography, Faculty of Mathematics and Natural Science, Universitas Indonesia, Depok, City, 16424, Indonesia \\ E-mail: ${ }^{1}$ ysupri@sci.ui.ac.id \\ ${ }^{b}$ Geospatial Information Agency, Jl. Raya Jakarta - Bogor KM. 46, Cibinong, 16911, Indonesia \\ E-mail: de2amri@gmail.com
}

\begin{abstract}
Traffic congestion is a problem for every city in Java Island, Indonesia, including Bogor City. Factors causing congestion in Bogor City are thought to come from land use, the geometry and performance of road, and public transport routes (urban transport). The change of urban transportation (angkot) route carried out by Bogor City Government aims to reduce traffic density and congestion, but it is not a guarantee that the main problem will be solved. This study aims to determine the spatial patterns of traffic density and congestion with current angkot routes and to construct a model to predict traffic density and congestion when new angkot routes are used. Variables in this research are land use (number of schools and markets/malls), geometry and performance of road (vehicle volume, road capacity, average velocity, road type, number of lanes, number of signalled and non-signal intersection), and an angkot route passing a road. The method used in modelling is multiple regression using one dummy variable and a stepwise regression method. The result of modelling shows that the variables affecting traffic density are velocity, some signalled and nonsignal intersection, and angkot route with $\mathbf{R}^{2}$ value $66.9 \%$. At the same time, the influential variables in the traffic congestion model are vehicle volume, road capacity, number of the signalled intersection, and angkot route with $R^{2}$ value $81.4 \%$. To see accuracy in predicting model of traffic density and congestion, Mean Absolute Percentage Error (MAPE) validation is used. The results show a value of $12.46 \%$ for traffic density, which means that the model has good prediction accuracy and $5.62 \%$ for traffic congestion, which means the model has high prediction accuracy. Thus, in this study, the land use of school and market is not a factor causing traffic density and congestion, while the geometry and performance of roads and public transportation routes as a factor causing congestion.
\end{abstract}

Keywords - spatial model; traffic congestion; multiple regression; routes of public transportation.

\section{INTRODUCTION}

Traffic congestion is the most common issue that happened in Asian countries which experiencing the multifaceted problem as a result of rapid urbanization [1]. Traffic congestion is a condition on road networks that are characterized by slower speeds, longer trip times, and increased vehicular queueing [2]. Many critical congestion areas in developing regions have poor traffic management systems, and the road network can result in a massive traffic jam for elongated periods [3]. Traffic congestion that happened in urban area slows the road movement, furthermore affect the rapid activities in urban areas [4]. Traffic congestion is also a problem for every region in Indonesia, including Bogor City. Factors causing congestion in Bogor City are considered as macro-level factors that are thought to come from land use, the geometry and performance of road, and public transport routes (urban transport) [5]. The change of urban transport (angkot) route carried out by the local government of Bogor City aims to reduce traffic density and congestion, but it is not a guarantee that the main problem will be solved. The number of preliminary routes before the route change is 23 routes after the local government publishes the rules then the most recent route number becomes 37 routes. Until now, the route change has not been fully implemented, one of which there is a road infrastructure that is not yet available. The study area of this research can be seen in Figure 1.

This study has topics towards the interaction among land use, transportation system, geometry, and road performance against traffic density and congestion in Bogor City. Similar research has been conducted in South Korea using weather and traffic data in predicting traffic congestion [5], another study was also conducted in Lagos, Nigeria to predict traffic congestion using traffic volume data [6].

This study aims to determine the spatial pattern of traffic density and congestion with the current route and construct a prediction model of traffic density and congestion when a new angkot route is used. By using multiple regression 
models can be known as the interaction between factors that affect traffic congestion, as well as to prove mathematically whether these factors are the cause of traffic congestion or not. The research using multiple regression model was conducted in Japan considering traffic factor, weather, and snow removal to predict the speed of the trip [7].

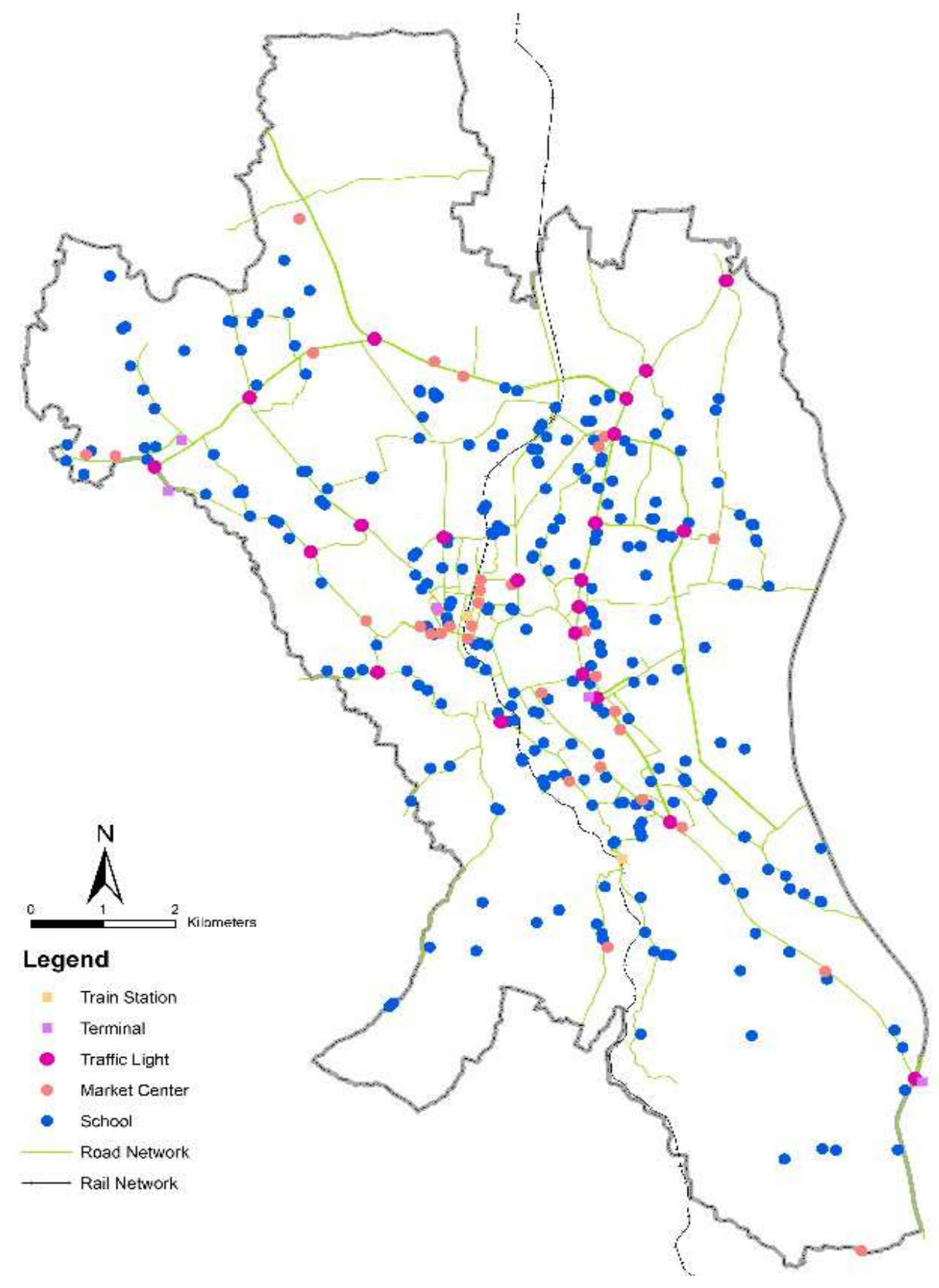

Fig 1. Study area in Bogor City

\section{MATERIALS AND METHODS}

Data used in this research are geometry data and road performance as well as the city transportation route, which is part of the transportation system obtained from the Department of Transportation in 2017. The data include road capacity, vehicle volume, average velocity, road type, number of lanes, number of signalled and non-signal intersection, and an angkot route. Meanwhile, land use data for a number of schools and market centres, both traditional and modern, was obtained from the identification of Topographic Map of Indonesia with scale of 1: 5,000 and field survey.

The data are used as variables to determine spatial patterns and construct a model to predict traffic density and congestion. Road type variables (one way, divided and undivided) are dummy variables because the data are categorical. In getting the number of schools and market centres using buffering techniques to the road segment as far as 100 meters from the location of schools and market 
centres, and have an influence. The number of road segments studied in this research is 175 road segments.

To measure the congestion level of a road segment is used, the congestion index is based on the average velocity of the vehicle and the free flow velocity. The research that uses velocity as an element in calculating the congestion index is done by [8] and [9]. The detection and analysis from the congestion index can provide information to plan and organize road traffic for traffic management. The congestion index formula can be seen in Equation (1).

$$
C I=\left\{\begin{aligned}
\frac{V}{V_{F F}} \times 100, & \text {; if } V \leq V_{F F} \text { and } V_{F F}>0 \\
100, & ; \text { if } V>V_{F F}
\end{aligned}\right.
$$

Where $\mathrm{CI}$ is the traffic congestion index of a road segment, $\mathrm{V}$ is the average velocity, and $\mathrm{V}_{\mathrm{FF}}$ is the maximum velocity or free flow. According to the Minister of Transportation Regulation [10], the maximum speed or free flow on urban roads is at most $50 \mathrm{~km} / \mathrm{h}$. The result of the congestion index is divided into 4 states as shown in Table 1.

TABLE I

CONGESTION INDEX

\begin{tabular}{|l|l|l|}
\hline $\begin{array}{c}\text { Congestion } \\
\text { Index }\end{array}$ & \multicolumn{1}{|c|}{$\begin{array}{c}\text { Traffic State } \\
\text { Level }\end{array}$} & \multicolumn{1}{|c|}{$\begin{array}{c}\text { Description of Traffic } \\
\text { State }\end{array}$} \\
\hline$[0-25]$ & Heavy Congestion & $\begin{array}{l}\text { The average speed is low, } \\
\text { road traffic state is poor }\end{array}$ \\
\hline$[25-50]$ & Mild Congestion & $\begin{array}{l}\text { The average speed is lower, } \\
\text { road traffic state is bit weak }\end{array}$ \\
\hline$[50-75]$ & Smooth & $\begin{array}{l}\text { The average speed is higher, } \\
\text { road traffic state is better }\end{array}$ \\
\hline$[75-100]$ & Very Smooth & $\begin{array}{l}\text { The average speed is high, } \\
\text { road traffic state is good }\end{array}$ \\
\hline
\end{tabular}

The multiple regression model is used by a stepwise regression method to get variables that influence traffic density and congestion. To find out the contribution of the independent variable to the dependent variable hence used coefficient determination $\left(R^{2}\right) . R^{2}$ is also often called the proportion of variation described by independent variables [11]. However, although the value of $\mathrm{R}^{2}$ is large, it does not necessarily mean that the regression model will be accurate in predicting. Therefore, model validation is required using various methods. Besides, to see the effect of independent variables on the dependent variable is also used the value of significance or $p$-value. The value of the p-value used is 0.05 as the limit of an independent variable affects the dependent variable.

To see accuracy in predicting the model of traffic density and congestion that has been constructed, Mean Absolute Percentage Error (MAPE) is used. This approach is useful when the size of the prediction variable is important in evaluating the prediction accuracy. Based on [12] and [13], the formula of MAPE is

$$
M A P E=\frac{1}{n} \sum_{t=0}^{n}\left|\frac{A_{t}-F_{t}}{A_{t}}\right|
$$

Where $\mathrm{n}$ is the amount of data, $\mathrm{A}_{\mathrm{t}}$ is the actual value, and $\mathrm{F}_{\mathrm{t}}$ the predicted value of the modelling result. The size of the MAPE value measures the accuracy of a model. The predicted accuracy value based on the MAPE value can be seen in Table 2.

TABLE II

MAPE VALUE TO FORECAST EVALUATION

\begin{tabular}{|l|l|}
\hline \multicolumn{1}{|c|}{ MAPE (\%) } & \multicolumn{1}{c|}{ Evaluation } \\
\hline MAPE $\leq 10 \%$ & High Accuracy \\
\hline $10 \%<\mathrm{MAPE} \leq 20 \%$ & Good \\
\hline $20 \%<\mathrm{MAPE} \leq 50 \%$ & Reasonable \\
\hline MAPE $>50 \%$ & Inaccurate \\
\hline
\end{tabular}

\section{RESULT AND DISCUSSION}

The result of model development shows that in predicting traffic density $\mathrm{R}^{2}$ value obtained is $66.9 \%$ with variables affecting traffic density are velocity, number of signalled and non-signal intersection, and angkot route. Equation 3 shows the results of multiple regression models for traffic density.

$\mathrm{Y}=322.362-4.836_{X 1}+6.754_{X 2}+17.273_{X 3}+2.089_{X 4}(3)$

where, $x 1$ is velocity, $x 2$ is angkot route, $x 3$ is signalled intersection, and $X_{4}$ is non signal intersection.

Meanwhile, the traffic congestion model obtained $\mathrm{R}^{2}$ value of $81.4 \%$ with variables that affect traffic congestion is vehicle volume, road capacity, number of the signalled intersection, and angkot route. The Equation of the result of the traffic congestion model can be seen in Equation 4.

$$
\mathrm{Y}=322.362-4.836_{X 1}+6.754_{X 2}+17.273_{X 3}+2.089_{X 4}(4)
$$

where, $x_{1}$ is velocity, $x_{2}$ is angkot route, $x_{3}$ is signalled intersection, and $X_{X 4}$ is non signal intersection.

In obtaining the accuracy of the model predictions, MAPE validation is used with results show that the accuracy for the traffic density model has a value of $12.46 \%$, which means that the model has good prediction accuracy. While the traffic congestion model has a value of $5.62 \%$, which means the model has a high prediction accuracy [14].

The spatial pattern of traffic density based on-road performance data describing the current condition can be seen in Figure 2.a. If the new angkot route is used to the traffic density model, then the spatial pattern will be seen in Figure 2.b. The traffic congestion pattern obtained by calculating the value of the congestion index, according to equation 1 can be seen in Figure 3.a. If a new angkot route is entered into the traffic congestion model, then the visualization can be seen in Figure 3.b.

New angkot routes are used in the model to see if local government policies affect density and traffic congestion. The calculation shows that the change of angkot route impacts the decreasing density value as much as 119 road segments or $68 \%$, while the density value which increases as much as 56 road segment or $32 \%$. The number of road segments with a density value of more than $250 \mathrm{~km} / \mathrm{km}^{2}$ also 
went down from 23 to 22 road segments. Meanwhile, in predicting traffic congestion using new angkot routes, 9 road segments were initially current status into mild congestion, so 13 road segments have mild congestion traffic status after the new angkot route is inserted.

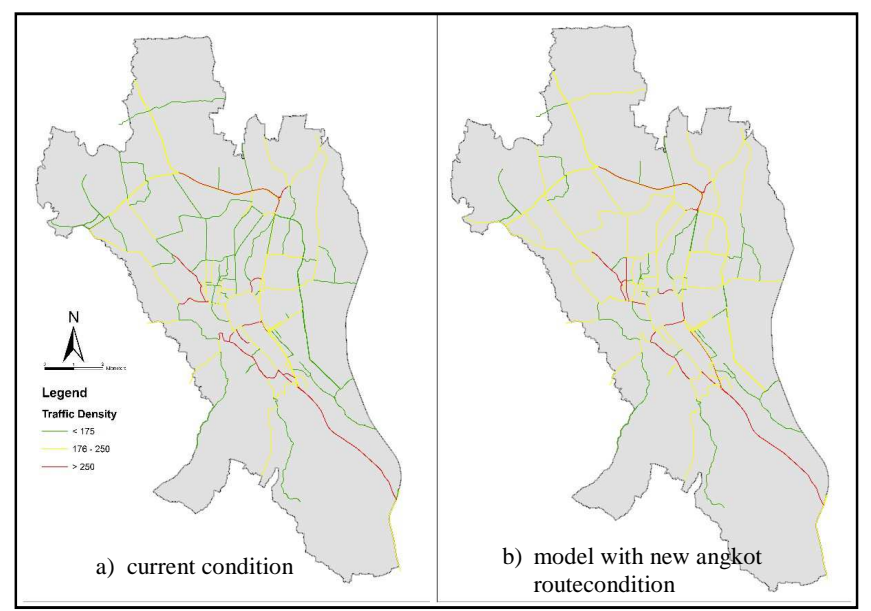

Fig 2. Traffic density

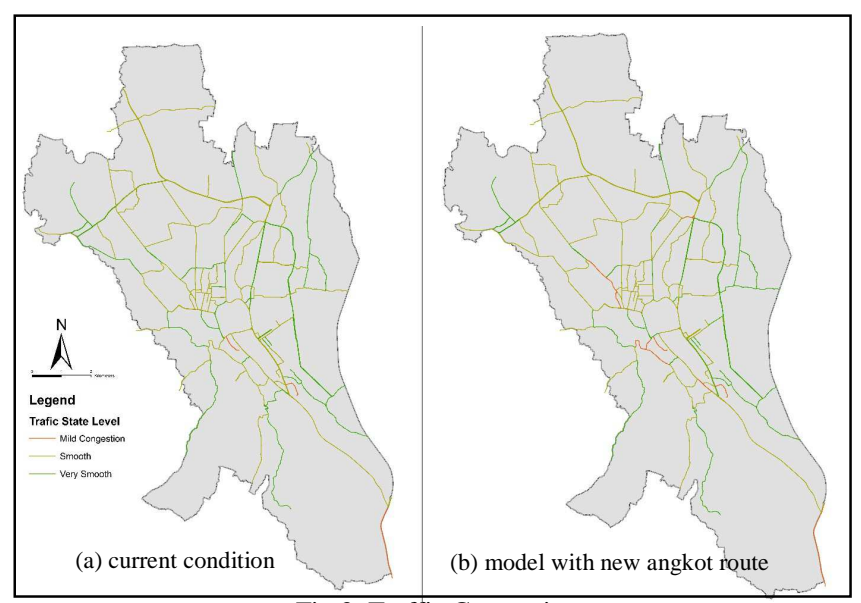

Fig 3. Traffic Congestion

\section{CONCLUSIONS}

The results of model development show that the land use of school and market is not a factor causing traffic density and congestion, while the geometry and road performance with variable velocity, number of signalled and non-signal intersection, and angkot route have an effect on traffic density. Meanwhile, the variables that affect traffic congestion are vehicle volume, road capacity, number of signalled intersections, and angkot route. The results also show that the policies made by the local government influence the decrease in the value of traffic density, although, in traffic congestion, there are 9 roads segment that previously had traffic status smoothly into mild congestion, although the calculation shows that the overall value of the congestion index decreased.

\section{ACKNOWLEDGMENT}

This research is financially supported by Universitas Indonesia grant PITTA Project Universitas Indonesia. Data for this study was provided by Geospatial Information Agency and Department of Transportation of Bogor City government.

\section{REFERENCES}

[1] A. M. Absar, A. Faisal. Urban Transport System and Congestion: A Case Study of Indian Cities. Transport and Communications Bulletin for Asia and the Pacific No.82, 33-41, 2013.

[2] W. Xiang-Wan, G. Rui-Jun, Yu Jing. Research on road traffic congestion index based on comprehensive parameters: Taking Dalian city as an example. Advances in Mechanical Engineering Vol. 10, 2018.

[3] J. Vipin, S. Ashlesh, and S. Lakshminarayanan, Road Traffic Congestion in the Developing World. Georgia: Proceedings of the 2nd ACM Symposium on Computing for Development, 11, 1-10, 2012.

[4] R. Shekhar.K, and Saharkar. U. Journal of Information, Knowledge, and Research in Civil Engineering, Vol. 3, 160-163, 2014.

[5] R. Amundapuran. M, and R. K. International Journal for Traffic and Transport Engineering Vol. 2, 286-305, 2012.

[6] Lee, J., Hong, B., Lee, K., \& Jang, Y-J. A Prediction Model of Traffic Congestion Using Weather Data. Proceedings of IEEE International Conference on Data Science Data Intensive System, 81$88,2015$.

[7] Olusina, J.O., \& Samson, A.P. International Journal of Engineering and Applied Science. 5 (2), 25-35, 2014.

[8] Hong, S., Hagiwara, T., Takeuchi, S., \& Lu, B. Journal of the Eastern Asia Society for Transportation Studies, 11, 1029-1046, 2015.

[9] Dias, C., Miska, M., Kuwahara, M., \& Warita, H. Relationship between congestion and traffic accidents on expressways: an investigation with bayesian belief network. Proceedings of $40^{\text {th }}$ Annual Meeting of Infrastructure Planning (JSCE), Japan, 2009.

[10] He, F., Yan, X., Liu, Y., \& Ma, L. Journal of Procedia Engineering. 137, 425-433, 2016.

[11] Regulation of the Minister of Transportation No. 111 Year 2015. Regarding the Procedures for Determining Speed Limits.

[12] Montgomery, D.C., Peck, E.A., \& Vining, G.G. Introduction to Linear Regression Analysis Fifth Edition. New Jersey: John Wiley \& Sons, Inc, 2012.

[13] Lewis, C.D. (1982). International and Bussiness Forecasting Methods. London: Butterwhorths.

[14] Myttenaere, A.D., Golden, B., Grand, B.L., \& Rossi, F. Mean Percentage Error for Regreesion Models. 23rd European Symposium on Artificial Neural Networks (ESANN 2015), 192, 38-48, 2016. 